\title{
Bowel perforation presenting three months after suprapubic catheter insertion
}

\author{
Thomas Stonier, ${ }^{1}$ Nick Simson, ${ }^{1}$ Elizabeth Wilson, ${ }^{2}$ Konstantinos Eleftherios Stergios ${ }^{3}$
}

'Department of Urology, Princess Alexandra Hospital NHS Trust, Harlow, UK

${ }^{2}$ School of Medicine and Dentistry, University of Bristol, Bristol, UK

${ }^{3}$ General Surgery, Watford General Hospital, Watford, UK

\section{Correspondence to}

Dr Thomas Stonier,

tomstonier@gmail.com

Accepted 23 August 2017

\section{SUMMARY}

An 82-year-old male with multiple comorbidities, including previous laparotomies, had a suprapubic catheter (SPC) inserted under guidance with ultrasound and a flexible cystoscope. Three months following the procedure, having returned for a flexible cystoscopy for ongoing bladder pain syndrome, he became peritonitic postoperatively.

A CT scan and subsequent laparotomy confirmed the SPC to be passing through a section of terminal ileum. The bowel was resected and he recovered well after a long hospital admission. A literature search found this delayed presentation of bowel perforation following SPC insertion to be rare, with only a few other cases reported. In particular, previous abdominal surgery increases the risk of this complication. This case serves as a reminder of the rare but potentially significant risk of SPC insertion and unusually highlights that this may not present immediately.

\section{BACKGROUND}

Suprapubic catheter (SPC) insertion can be a simple and safe procedure, in particular when guided with ultrasound and a flexible cystoscope by an experienced urologist. However, the recognised life-threatening complication of bowel injury is always at the forefront of the surgeon's mind, even more so in patients with previous abdominal surgery. Typically, this complication presents immediately. This case serves not only as a reminder of this serious complication, but as further evidence that it may have a delayed presentation.

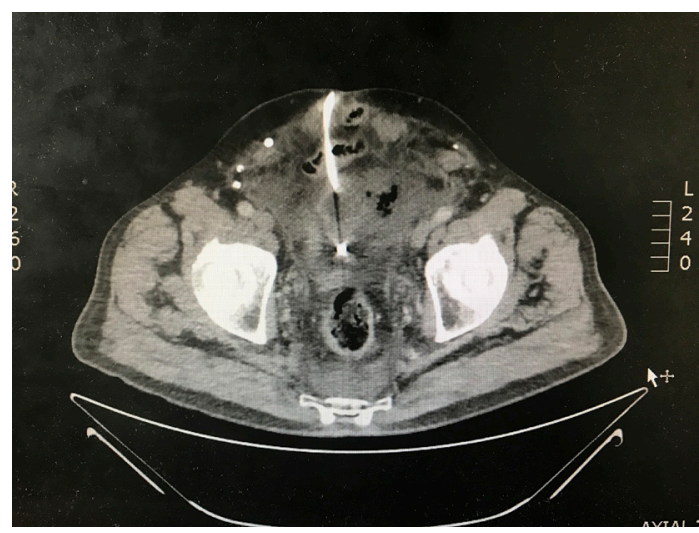

Figure 1 A slice from the CT abdomen and pelvis showing the suprapubic catheter perforating the terminal ileum and entering the bladder.

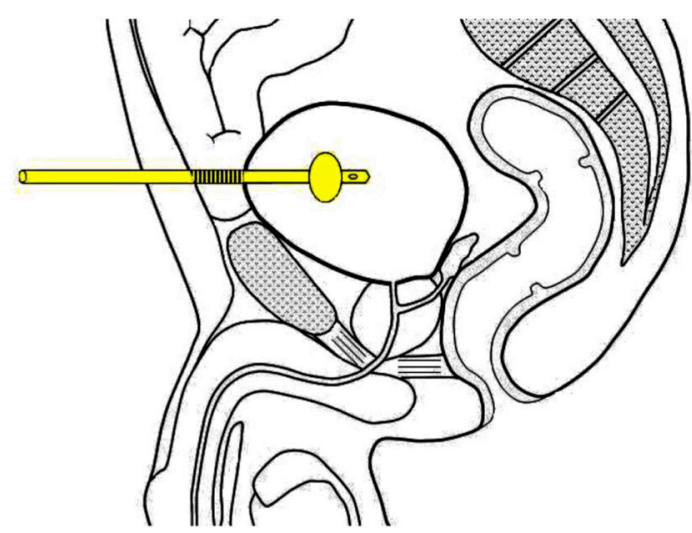

Figure 2 A diagram representing the CT findings. Copyright and with permission from Ahmed et al. ${ }^{1}$

\section{CASE PRESENTATION}

In September 2016, an 82-year-old male with painful bladder syndrome, a wide bladder neck and small bladder capacity opted to undergo an elective SPC insertion as he was unable to tolerate a long-term urethral catheter. His surgical history was significant with two laparotomies: an anterior resection and a subsequent emergency further bowel resection. His medical history included two myocardial infarctions, a cardiac stent, stage 3 chronic kidney disease, a $4.4 \mathrm{~cm}$ abdominal aortic aneurysm, hypercholesterolaemia and diverticular disease.

The risks and benefits of having an SPC were discussed prior to the patient consenting for the procedure, and the possibility of bowel injury, in light of his surgical history, was made clear. Despite this, the patient opted to go ahead with the procedure, as he felt the benefits outweighed the risks in his case.

Two surgeons, a specialty registrar and a consultant, performed the procedure. An initial flexible cystoscopy showed inflammatory changes and a small bladder capacity of around $200 \mathrm{~mL}$. At the time of procedure, the bladder was over-distended and contained $500 \mathrm{~mL}$. The second surgeon, trained and experienced in ultrasound use, assessed the distended bladder with ultrasound and saw no bowel visible between skin and bladder. A Seldinger technique was then adopted; a needle was introduced into the bladder successfully on the first attempt via a puncture to the right of the midline to avoid a midline scar $2 \mathrm{~cm}$ above the pubic bone. The guidewire was then inserted through the needle, and under cystoscopic guidance the trocar 


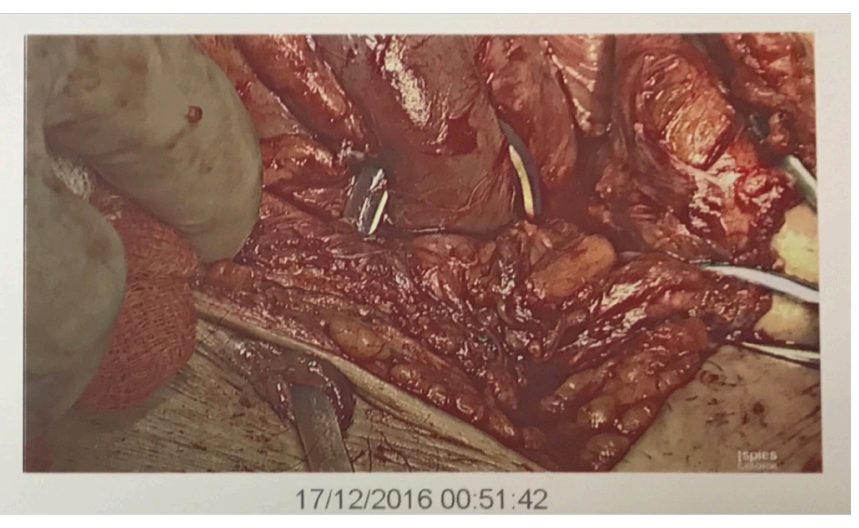

Figure 3 A photograph taken in theatre showing the catheter entering the skin (bottom left of image), perforating the terminal ileum through a fibrosed track and entering the bladder (out of picture in centre of image).

was introduced into the bladder. A two-way, 16 Fr SPC was then inserted and its position checked with the cystoscope. Initially blood was seen draining into the catheter, but this became clear. The patient recovered well, with no features of abdominal pain or peritonism, and was discharged home the next day.

\section{INVESTIGATIONS}

Three months later, the patient returned for further assessment as he continued to experience painful bladder symptoms. Cystoscopic investigation and a bladder biopsy were carried out, but the SPC was not changed at this time. Following the procedure, the patient started to complain of abdominal pain and was found to be peritonitic. His blood tests revealed no abnormality. A CT scan was ordered, which showed the SPC passing through the small bowel, as shown in figures 1 and $2 .^{1}$ The CT also demonstrated that there were moderate amounts of extraluminal air and free fluid within the abdomen and pelvis, indicating bowel perforation. The SPC is seen passing through the skin $18.5 \mathrm{~mm}$ from the pubic symphysis (British Association of Urological Surgeons (BAUS) guidelines state this distance should be less than $2 \mathrm{~cm}$ ).

\section{OUTCOME AND FOLLOW-UP}

The patient returned to theatre for a laparotomy where the SPC was found to be passing directly through the terminal ileum into the bladder as shown in figure 3, with areas of fibrosis around it. Several loops of small bowel were directly adherent to the rectus sheath. The affected area of bowel was resected and the catheter left in situ. The patient made a slow but successful postoperative recovery.

\section{DISCUSSION}

SPC insertion is a common urological procedure that can be associated with serious complications. A 2006 retrospective cohort study of 219 patients who had SPCs inserted at two separate urological centres over an 8-year period demonstrated an intraoperative complication rate of $10 \%$ and a 30 -day complication rate of $19 \% .^{2}$ The most common complications were urinary tract infection (21\%) and catheter blockage (25\%). However, rarely, more serious complications occur, such as bowel perforation $(0.2 \%)$ which may prove fatal; the overall mortality rate in the study by Ahluwalia et al was $1.8 \% .^{2}$

The most likely time for patients with perforations to present is in the few days following the procedure. ${ }^{3}$ However, there have been several reports of delayed presentation of bowel perforations. Some of these have occurred following the first change of the catheter, ${ }^{145}$ others have presented up to 3 years later. $^{6}$ It may be that the perforation is sealed by the catheter itself and the ensuing inflammatory fibrosis that occurs following insertion. In this case, it is likely that the preceding cystoscopy and bladder distension played a role in the change in the patient's symptoms and subsequent diagnosis of bowel perforation.

One of the most significant risk factors for bowel perforation is previous abdominal surgery as these procedures may leave patients with significant intra-abdominal adhesions. Given the anatomical location of the bladder, this is particularly the case for those who have had previous lower abdominal surgery, as they are more likely to have adhesions in the pathway of SPC insertion. ${ }^{7}$ Guidelines published in 2011 by the BAUS do not list previous lower abdominal surgery as a contraindication to SPC insertion, but advise that more caution must be taken in these cases. ${ }^{8}$ It is recommended that ultrasound is utilised so that surgeons can quickly and easily visualise the contents of the abdomen below their insertion point to ensure that no bowel is present. However, given that this case led to perforation despite the use of ultrasound, it is clear that this will not prevent all cases of bowel injury.

The BAUS guidelines state the ultrasound must be performed by a clinician trained and experienced in this technique-as it was in this case. ${ }^{8}$ It should be noted there are no specific criteria in the guideline of what level of training and experience is required. By comparison, the Royal College of Radiologist guidelines require one ultrasound list per week and a minimum of 250 cases over 6 month to attain even a level 1 ultrasound qualification in Urology ultrasound-at this time there is no place for this in urological training. ${ }^{9}$ It is excessive to suggest all ultrasounds for SPC insertion must be performed by a trained ultrasonographer/radiologist, given a clear benefit of extra information in all cases. However, this case suggests that the technique may not be completely reliable in patients with distorted anatomy due to adhesions (possibly due to reduced intraluminal gas), and in these patients the support of a trained ultrasonography/radiologist should be sought. A further consideration for the urologist in these cases is whether an open cystotomy and SPC insertion would offer a safer procedure allowing for direct visualisation of the tract being formed.

The BAUS guidelines emphasise the importance of watching for signs of bowel injury in patients with an SPC. ${ }^{8}$ Patients with an SPC who present with features of peritonitis accompanied by other signs of bowel injury, such as a raised temperature and a high white cell count, should be assessed and managed efficiently in order to prevent any further deterioration.

\section{Learning points}

- Bowel injury following suprapubic catheter (SPC) insertion is a rare but life-threatening complication.

- Previous abdominal surgery is a major risk factor for bowel injury secondary to SPC insertion.

- Bowel injury following SPC insertion may present at any time following the procedure, even months or years later.

- Ultrasound and flexible cystoscopy-guided SPC is not infallible. Imaging by a trained ultrasonographer/radiologist or open cystotomy should be considered in difficult cases such as these. 
Despite the potential risks, SPCs have a high satisfaction rate of $72 \%$, with $82 \%$ of patients preferring SPCs to urethral catheters. ${ }^{1}$ Efforts must be made by urologists and other healthcare professionals involved in the care of patients with SPCs to ensure that patients are aware of the risk of bowel injury prior to the procedure, that all preventative measures are taken and any complications are detected and managed effectively whether immediate or delayed.

Contributors TS contributed to the conception and design of the study. TS and NS were involved in the planning and data acquisition. TS, NS and EW were responsible for the conduct and reporting. Drafting article was done by TS and EW. All authors equally contributed to the revision of the article, final approval and agreed to be accountable for the work.

Competing interests None declared.

Patient consent Obtained.

Provenance and peer review Not commissioned; externally peer reviewed.

(c) BMJ Publishing Group Ltd (unless otherwise stated in the text of the article) 2017. All rights reserved. No commercial use is permitted unless otherwise expressly granted.

\section{REFERENCES}

1 Ahmed SJ, Mehta A, Rimington P. Delayed bowel perforation following suprapubic catheter insertion. BMC Urol 2004:4:16.

2 Ahluwalia RS, Johal N, Kouriefs C, et al. The surgical risk of suprapubic catheter insertion and long-term sequelae. Ann R Coll Surg Engl 2006;88:210-3.

3 Bonasso PC, Lucke-Wold B, Khan U. Small bowel obstruction due to suprapubic catheter placement. Uro Case Rep 2016;7:72-3.

4 Kass-lliyya A, Morgan K, Beck R, et al. Bowel Injury after a routine change of suprapubic catheter. BMJ Case Rep 2012;2012:bcr2012006524.

5 Witham MD, Martindale AD. Occult transfixation of the sigmoid colon by suprapubic catheter. Age and Aging 2002;31:407-8.

6 Gallagher KM, Good DW, Brush JP, et al. Small bowel injury after suprapubic catheter insertion presenting 3 years after initial insertion. BMJ Case Rep 2013;2013:bcr2013201436.

7 Levrant SG, Bieber EJ, Barnes RB. Anterior abdominal wall adhesions after laparotomy and laparoscopy. J Am Assoc Gynecol Laparosc 1997;4:353-6.

8 Harrison SC, Lawrence WT, Morley R, et al. British association of urological surgeons' suprapubic catheter practice guidelines. BJU Int 2011;107:77-85.

9 The Royal College of Radiologists. Ultrasound training recommendations for medical and surgical specialities. 2nd edn, 2012. https://www.rcr.ac.uk/system/files/publication/ field_publication_files/BFCR(12)17_ultrasound_training.pdf (accessed 9 Jul 2017).

Copyright 2017 BMJ Publishing Group. All rights reserved. For permission to reuse any of this content visit http://group.bmj.com/group/rights-licensing/permissions.

BMJ Case Report Fellows may re-use this article for personal use and teaching without any further permission.

Become a Fellow of BMJ Case Reports today and you can:

- Submit as many cases as you like

- Enjoy fast sympathetic peer review and rapid publication of accepted articles

- Access all the published articles

- Re-use any of the published material for personal use and teaching without further permission

For information on Institutional Fellowships contact consortiasales@bmjgroup.com

Visit casereports.bmj.com for more articles like this and to become a Fellow 